\title{
Importance of Business Intelligence Solution on Decision-Making Process of Companies
}

\author{
Serdar Biroğul ${ }^{1}$, H. Berk Gültekin*²
}

Accepted $3^{\text {rd }}$ September 2016

Abstract: Nowadays, many companies meet the needs of data from different data sources in different formats in order to in line with changing business needs. Data is managed and stored in different parts of the system. Business intelligence is the most effective solution that allows to see big picture by integrating all of the distributed data within a storage. Business intelligence has emerged as a natural result of the previous system designed to support the decision-making process. Over time, visual deficiencies discovered in decision support systems, difficulties of usages and mismatch between applications, is one of the major factors in the rise of business intelligence technology. Such solutions are up to date and integrated view of business performance it offers the greatest benefits to decision makers.

By increasing centralization of data quality, control and scheduling capabilities have allowed us to take quick and right decisions in the evolving competitive environment. The concept of business intelligence is an important element of taking strategic decisions and implementation point in globalized world. This study has designed by Oracle business intelligence tool and results have been a key element of evaluation in decision making processes of the companies.

Keywords: Decision making, business intelligence, big data.

\section{Introduction}

Rapid changes in the business life and complex situations that come along with these changes force businesses to make fast and accurate decisions. This journey started with the use of decision support systems which are being replaced by business intelligence technologies due to changing business needs.

Instead of depending on their personal predictions and intuition, decision makers must adopt approaches based on facts in order for companies to have competitive advantage. With the introduction of business intelligence tools, centralized data sources enhance data quality and control, as well as shortening decision-making and action-taking time by preventing decision makers from getting lost in different data sources. Centralized data sources may sometimes appear in the form of data warehouses and sometimes in the form of data marts containing department- or issue-specific solutions.

The number of studies in Turkey on business intelligence systems, which are recognized more and more by companies for their importance, is insufficient. The purpose of this study is to emphasize the effect of business intelligence solutions used in the finance sector, which has a direct relationship with money, on company strategies and explain their advantages for companies

\section{Strategic Decision-Making}

Strategic decisions have long-term and profound impacts. Access

\footnotetext{
${ }^{1}$ Computer Engineering Department, Technology Faculty, Düzce

University, Düzce/Turkey.serdarbirogul@duzce.edu.tr

$*^{2}$ Department of Business Intelligence, $R \& D$, Aktifbank,

Istanbul/Turkey

Corresponding Author: Email: berk.gultekin@aktifbank.com.tr

Note: This paper has been presented at the $3^{\text {rd }}$ International Conference on Advanced Technology \& Sciences (ICAT'16) held in Konya (Turkey), September 01-03, 2016.
}

to complete and accurate information in line with business needs on time has made decisions more structured. Data warehouses store the data constantly cleaned and updated with ETL (ExtractTransform-Load) processes, which are designed in a planned way, and fulfill the quality data element, which is one of the important factors in the decision-making process. Softwares that allows for the management of the business intelligence process contribute to the decision making process by bringing all the technical work to a level which the decision maker will understand using visual tools such as display panels, pivot tables or graphs.

Decision-making and action-taking occur after the intervention of many factors simultaneously. Considering today's conditions, competition between companies seem to be getting fiercer with each passing day with emerging technology. To be able to survive in the dynamic business life is not possible with adopting emerging technologies to the company alone. The cornerstone of fast and effective decision-making is to provide analyses designed in accordance with today's needs to competent decision makers who are able to accurately assess results of these analyses, which provides a considerable competitive advantage for companies.

It has been found in recent studies that most companies cannot use corporate data in decision-making processes efficiently. The amount of collected data increases exponentially with each passing day, which means that the competition between companies increases at the same pace. It is of great importance to have different and well-integrated information sources for an effective decision-making process. At this point, business intelligence is provision of a powerful, low-cost, easy-to-use and sharable source, which can meet the needs. The resulting heaps of information with changing technology were not useful to upper management.

A need for management information systems allowing for the presentation of integrated and summary data emerged. Decision 
support systems were developed for this purpose.

However, visual inadequacies, usage difficulties and integration problems between applications created the need for a new system to achieve this purpose and established a ground for the introduction of Business Intelligence Systems.

\section{Business Intelligence}

Business intelligence as a term was used for the first time in 1989 by Howard Dresner, who worked as an analyst and researcher at Gartner Group. Howard Dresner saw business intelligence as a decision support system based on facts and an umbrella covering all methods and ideas that enhance the ability of business-related decision-making.

Business intelligence application softwares are considered to be the latest point that decision support systems have reached. Therefore, they have a wider scope compared to decision support systems. They contain a higher level of analysis and more estimation algorithms. In addition, offering a powerful visual tool support is one of the important reasons why they are used widely today.

A well-designed technological infrastructure is not enough for a new solution to be adopted widely. To correctly describe and explain the philosophy behind the solution and its meaning is at least as important as the solution itself. Many definitions have been made for business intelligence to emphasize its contribution to the decision-making process and effectiveness of administrative decision-making [1 - 6].

Kraft Foods, which has its head office in Illinois, USA, employs about 125.000, has a annual revenue of USD 110 million with its more than 70 brand, has 40 brands in the market for more than 100 years and has an asset size of USD 49 billion and is the second biggest food company in the world, started to use SAP Business Objects BI 4.0 business intelligence application in 2012. The main purpose of the project was to make it possible to rapidly and effectively reach the rich data in the ERP system of the company through user-friendly interfaces. Mike Walsh, the Business Intelligence Director of Kraft Foods expressed his satisfaction with the installation and implementation by saying, "These solutions have made everything we do easier". In addition, improved query performance and more self-serve reporting across the company are other positive outcomes of the project.

Considering success stories with business intelligence softwares, the following are observed [7 - 8]:

- It is possible to access the desired data at the desired place through visual graphics comfortably and understandably without needing IT specialists,

- It is possible to access appropriate data among million lines of data in a shorter time and ensure a faster decision-making process,

- The huge amount of time spent for data tabulation and evaluation can be channelized to customers and decision makers,

- A lower number of key performance indicators are used,

- A higher level of report optimization is achieved,

- The simplification of data is much more comfortable.

\section{Experiments}

In terms of accounting and financial reporting, the information required by banks for analysis and interpretations such as the following is prepared in a standard way:

- Ensuring uniformity,
- Obtaining uniform balance sheets and income statements directly,

- Obtaining information required for auditing and supervision in a verifiable and auditable manner,

- Reaching information required by authorities to monitor and direct the economy and other statistical data,

- Financial analysis,

- Risk analysis,

- Efficiency analysis.

Oracle Business Intelligence 11.1.1.7.140527 was used in the implementation of the study. Within the scope of our study, we held meetings with finance group employees in different periods in order to determine business needs both verbally and in written. As a result of these meetings, the study was shaped on a business model covering technical analysis documents and queries that end-users desire and may desire in future.

Database which was used

- Oracle Database 11g Enterprise Edition Release 11.2.0.4.0 64bit Production

- PL/SQL Release 11.2.0.4.0 - Production

- CORE 11.2.0.4.0 - Production

- $\quad$ TNS for Linux: Version 11.2.0.4.0 - Production

- NLSRTL Version 11.2.0.4.0 - Production

Fig. 1 shows a screenshot related to one of the steps of creating the physical layer used in the study and Fig. 2 shows a screenshot related to displaying data.

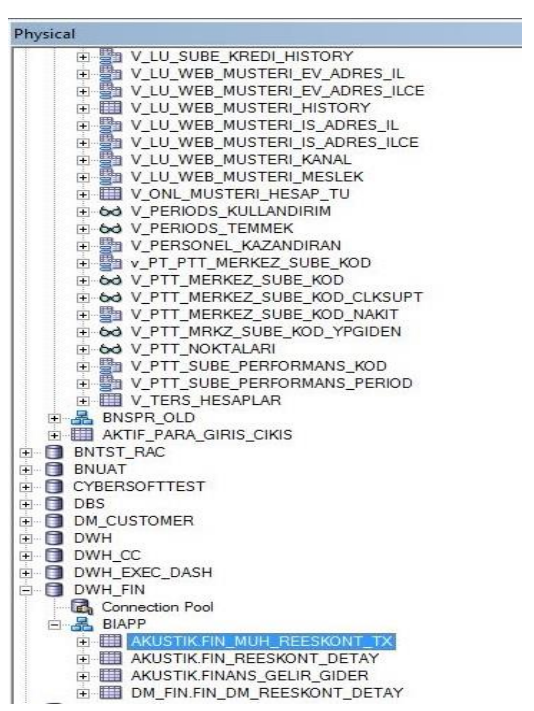

Figure 1. Creating physical layer tables.

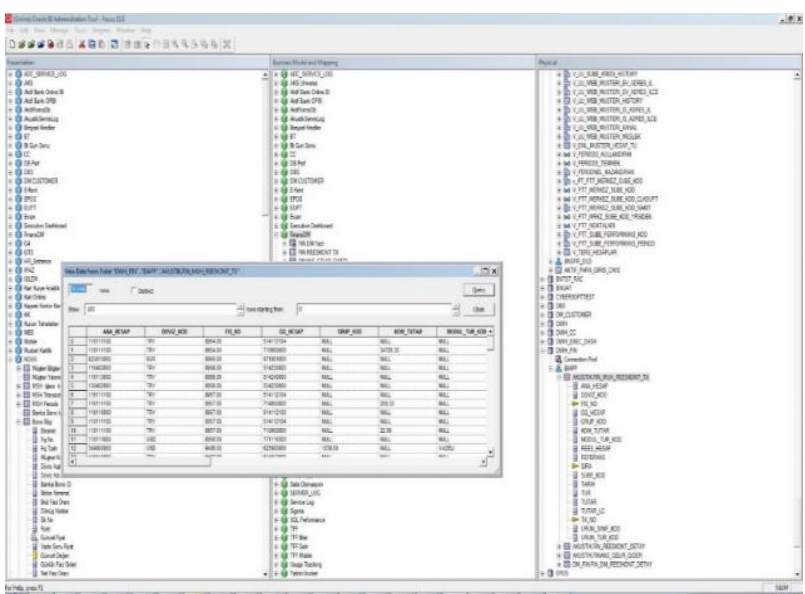

Figure 2. Displaying data 
Fig. 3-4-5 show screenshot related a few of the steps of creating the business model and mapping used in the study.

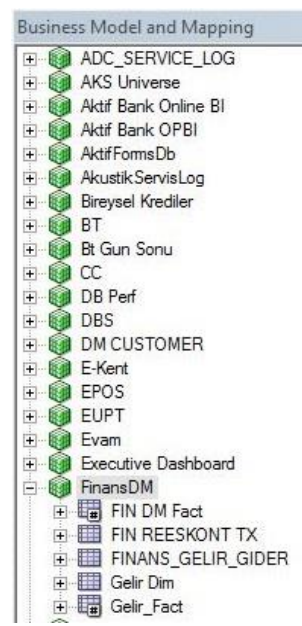

Figure 3. The current business model and mapping.

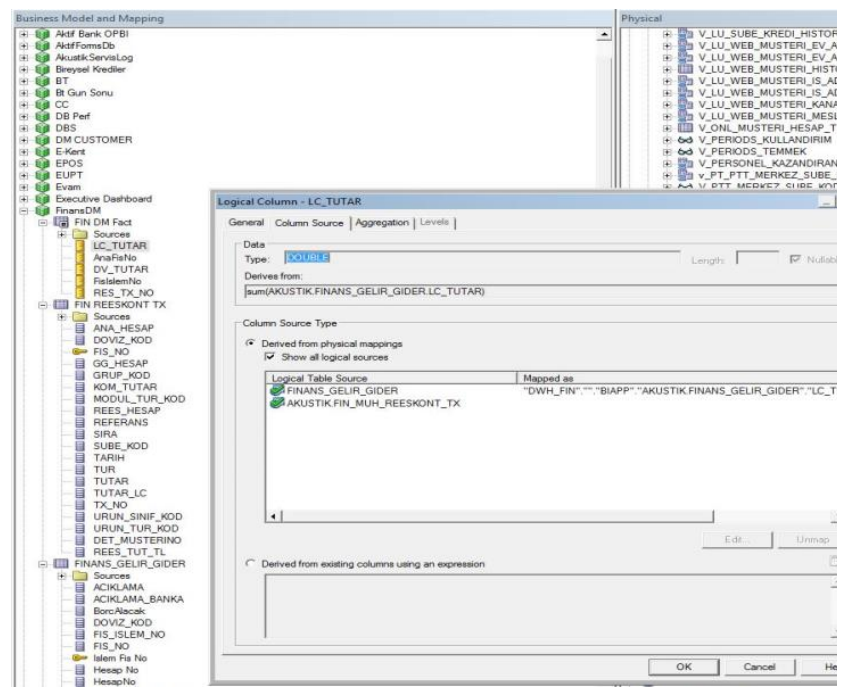

Figure 4. Business model and mapping fact table design-2.

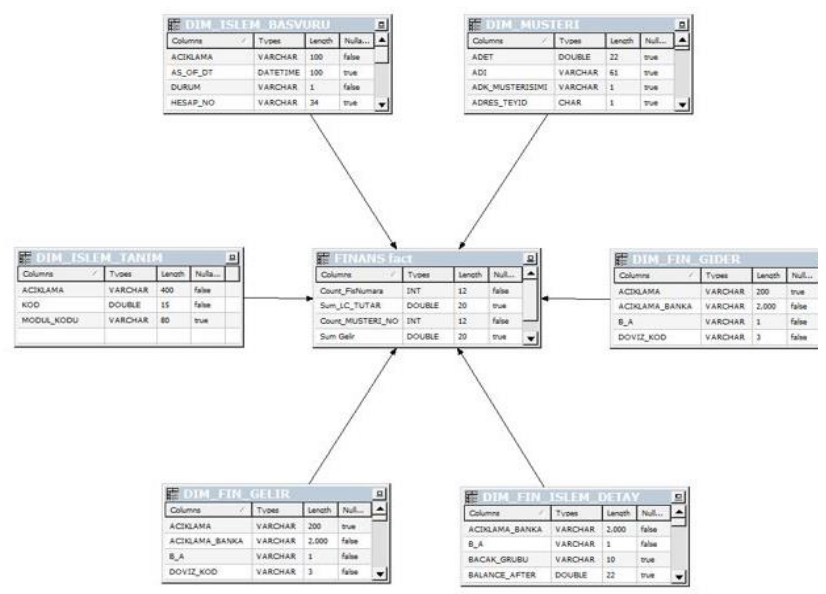

Figure 5. Displaying the business model and mapping table relations.

Fig.6. Shows a screenshot related to one of the steps of creating the presentation layer used in the study.

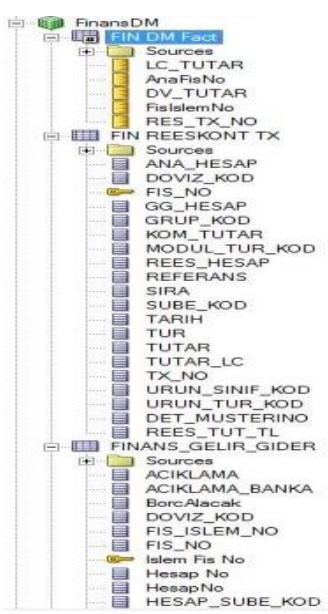

Figure 6. Displaying the presentation layer.

Business Intelligence Production

Oracle Business Intelligence web interface is a reporting tool that allows us to reach the data in the system in line with defined targets, perform analyses that make is possible to make healthy decisions and present these with visual richness. Once the Data Mart design, which is the first phase of the study, is completed, we can go on with the next phase, which is providing an Oracle web interface for end-users. This phase which emerges after needs analysis allows end-users to create reports using a drag and drop technology. The relevant screenshot is given in Fig.7.

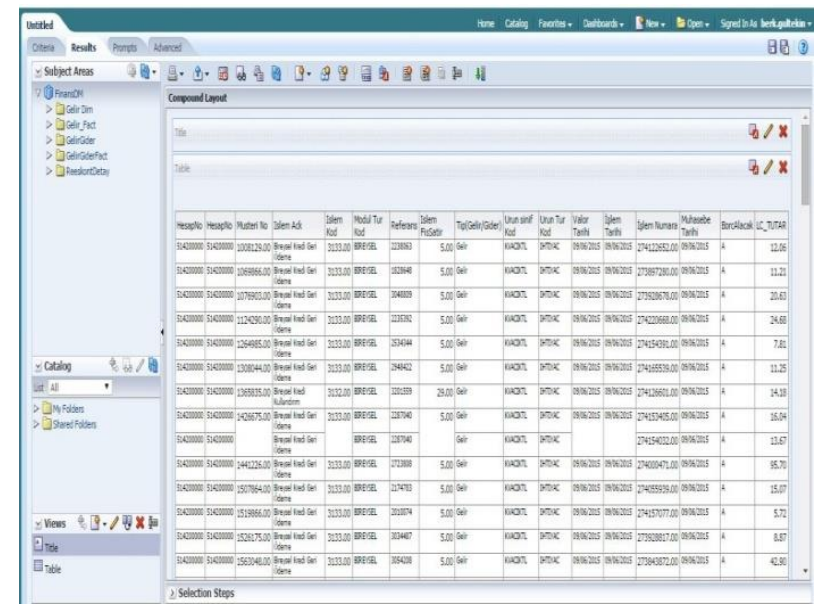

Figure 7. Displaying analysis results.

\section{Conclusion}

Reports obtained as a result of the solution designed within the scope of the study allows us to find customer details based on the ledger account number.

The solution, which began to be used by the finance group of the bank, allows us to find customer details based on the ledger account number and evaluate loans given or taken by the bank from a financial perspective. Requested data presents periodic profit and loss information to the bank. It also allows for a crosscheck between bottom totals of accounts found on the basis of customer and voucher number and bank balance, which is used a checking tool in accounting. These checks lay the groundwork for preparation of steps that will allow for healthier banking operations by detecting vouchers prepared for the wrong account number. For example, it is possible to make improvements in the current banking software thanks to detection of continuous mistakes. 
Also, long-term and short-term loan information that banks are obliged to report to the tax office periodically, constitute a resource for decisions related to loans for the government.

\section{Acknowledgements}

This study, which the project number was 2016.07.02.408, was supported by Scientific Research and Projects Coordinatorship, Duzce University.

\section{References}

[1] G.J. Miller, D. Bräutigam and S.V. Gerlach, Business Intelligence Competency Centers, John Wiley \& Sons, Inc., 2006

[2] (2015)http://www.lodestonemc.com/files/pdf/success_stori es.

[3] H. Ateş, "Karar Vermede İş zekasının Önemi Tekstil Sektöründe Bir araştırma", Yüksek Lisans Tezi, Dokuz Eylül

Üniversitesi, 2008.

[4] A.S. Yılmaz, "Esnek raporlama aracı ve iş zekası uygulamaları ile bütünleştirilmesi”, Yüksek Lisans Tezi, Ege Üniversitesi, 2010.

[5] M. Gibson, D. Arnott, and I. Jagielska, "Evaluating the Intangible Benefits of Business Intelligence Review \& Research Agenda", Proceedings of the 2004 IFIP International Conference, 2004, s. 295-305.

[6] J. Reinschmidt, and A. Francoise, IBM Business Intelligence Certification Guide, pp.3-4, 2000.

[7] (2015) Hannon, http://sapinsider.wispubs.com/Assets/CaseStudies/2012/April/Kraft-Foods-Recipe-For-SuccessfulBusiness-Intelligence.

[8] (2015)Crider,http://www.sap.com/customertestimonials/high-tech/dell.html. 